REVIEW

\title{
Amyloid in the cardiovascular system: a review
}

\author{
I Kholová, H W M Niessen
}

J Clin Pathol 2005;58:125-133. doi: 10.1136/icp.2004.017293

The cardiovascular system is a common target of amyloidosis. This review presents the current clinical and diagnostic approach to amyloidosis, with the emphasis on cardiovascular involvement. It summarises recent nomenclature, classification, and pathogenesis of amyloidosis. In addition, non-invasive possibilities are discussed, together with endomyocardial biopsies in the diagnosis of cardiac amyloidosis. Finally, recent advances in treatment and prognostic implications are presented.
See end of article for authors' affiliations

Correspondence to: Dr H W M Niessen, Vrije Universiteit Medical Centre, Department of Pathology, De Boelelaan 1117, Room 1B116, 1007 MB Amsterdam, The Netherlands; jwm.niessen@vumc.nl

Accepted for publication 26 August 2004
A myloidosis is a generic term that encompasses a large group of diverse diseases rather than a single disease entity. By definition, the only diagnosis of amyloidosis is morphological assessment of cytological/histological or postmortem material. Despite the fact that morphologically proteinaceous deposits are identical, these proteins are chemically different and can be identified and classified by immunohistochemical/biochemical analysis. The primary structure of these proteins is crucial to the formation of amyloid, its sites of deposition, and the clinical symptoms. Amyloid deposits may be found in any part of the body. Remarkably, amyloid may be found in the absence of clinical manifestations.

\section{DEFINITION, NOMENCLATURE, AND CHEMICAL CHARACTERISTICS}

Amyloidosis is characterised by the extracellular deposition and accumulation of insoluble fibrillar proteins, with concomitant destruction of normal tissue structure and function. Amyloid fibrils are arranged in an antiparallel conformation with a $\beta$ pleated sheet structure. ${ }^{1-3}$ It is recommended that amyloid and amyloidosis should be classified by the fibrillar protein forming the amyloid deposits. The current nomenclature of amyloidosis is based on the nature of the major fibrillar protein, which is designated protein A, followed by an abbreviation of the protein name. Eighteen proteins, 19 if lactoferrin is included, have been identified to date. $^{4-6}$ Table 1 summarises the main protein types causing amyloidosis.

\section{"It is recommended that amyloid and amy- loidosis should be classified by the fibrillar protein forming the amyloid deposits"}

In addition to the fibrils, which characterise the material as amyloid, it contains other components, which are common to most types of amyloid. These include serum amyloid P component, amyloid enhancing factor, and glycosaminoglycans. Other basement membrane components, including fibronectin, laminin, and collagen IV, may also be found in amyloid deposits. $^{7-9}$

\section{PATHOPHYSIOLOGY}

Although at least 18 different amyloidogenic proteins have been recognised, identical processes are probably involved in the formation of the amyloid fibrils, which are remarkably similar to each other, despite the biochemical differences. Protein species with a conformation that allows ordered self assembly are needed for fibril formation. The process is performed either by partial unfolding of the native protein (for example, light chain immunoglobulin), by proteolytic cleavage (for example, lactadherin), or by adoption of a secondary structure in a peptide with a random coil. Many precursors of amyloid play a role as molecular carriers, others form multipeptide complexes. ${ }^{3} 1011$

The mechanism by which amyloid aggregation causes tissue damage and consequent organ dysfunction has been widely discussed and studied. Amyloid deposition can disturb the tissue architecture and lead to organ dysfunction. Local cytotoxicity and interactions with local receptors can also influence organ function. $^{3}{ }^{10}$ Free radical injury mechanisms have been suggested in amyloidogenesis in several types of amyloidosis. ${ }^{12}$ Recently, it has been shown that light chain proteins from patients with amyloid cardiomyopathy can alter the cellular redox state in cultured cardiomyocytes. ${ }^{13}$ In addition, both in vivo and in vitro evidence has shown that amyloid can induce apoptosis. $^{1415}$

\section{CLINICAL CLASSIFICATION}

In clinical practice, amyloidosis is classified as primary, secondary, hereditary, and age related. ${ }^{16}$ Primary (idiopathic, systemic) amyloidosis appears with no antecedent or coexisting disease, it involves mesenchymal organs such as the cardiovascular system, gastrointestinal tract, and muscle tissue, and tends to form nodular deposits. Cardiac involvement is common. ${ }^{16-18}$ Secondary (reactive) amyloidosis is associated with chronic diseases, and has a tendency to deposit in parenchymal organs such as the liver, spleen, and kidneys. The heart is involved only rarely. ${ }^{16}{ }^{19}$ The hereditary amyloidoses are usually inherited in an autosomal dominant fashion, ${ }^{20}{ }^{21}$ with only a few autosomal recessive forms such

Abbreviations: $A N F$, atrial natriuretic factor; IAA isolated atrial amyloidosis; SAA, serum amyloid A; SSA, systemic senile amyloidosis; TRR, transthyretin 
Table 1 Main protein types causing amyloidosis with the emphasis on cardiovascular system involvement



as familial Mediterranean fever ${ }^{22}$ and familial corneal amyloidosis. ${ }^{23}$ Cardiac involvement is rare and usually occurs late in the disease. ${ }^{162124}$ Age related (elderly) amyloidosis is classified as either the isolated atrial form or the systemic senile type. Age is the only risk factor. The incidence increases with aging and is not related to concurrent disease. The heart is the main target. ${ }^{25-29}$

\section{CARDIAC CLINICAL MANIFESTATIONS}

In general, the symptoms of amyloidosis are non-specific. Cardiac amyloid involvement may simulate cardiomyopathy, congestive heart failure, coronary heart disease, valvular heart disease, or arrhythmia. ${ }^{16-18}{ }^{30-34}$ Table 2 lists the clinical features of cardiac amyloid involvement. Unusual features include spontaneous resolution of hypertension and hemi blocks. $^{34}$

Initial symptoms that might lead to the suspicion of cardiac amyloidosis include fatigue, dyspnoea, purpura, macroglossia, atypical chest pain, hepatomegaly, peripheral oedema, arrhythmia, and systolic murmur. Predominantly right sided heart failure is the most common clinical feature. In addition, coronary heart disease is often incorrectly diagnosed..$^{16} 3435$

Of note is the male and age preponderance: $60-65 \%$ of patients with amyloidosis are men and only $1 \%$ of patients are younger than 40 years of age. ${ }^{35}$

Table 2 Cardiac clinical manifestations of amyloidosis

Clinical characteristics of cardiac amyloid involvement

Dilated cardiomyopathy (cardiomegaly, predominant systolic dysfunction)

Restrictive cardiomyopathy (slight cardiomegaly, predominant diastolic dysfunction, stiff heart syndrome)

Congestive heart failure

Electrocardiographic disorders (rhythm abnormalities, low voltage QRS complex, sick sinus syndrome, pseudoinfarct pattern, atrioventricular and ventricular conduction abnormalities)

Coronary insufficiency (myocardial infarction, angina pectoris)

Valvular dysfunction

Pericardial tamponade

Enhanced sensitivity to digitalis glycosides

Atrial thrombosis-embolisation

\section{DIAGNOSIS}

The expanding number of amyloidogenic proteins causes difficulties in formulating a correct diagnosis. The identification of amyloidogenic proteins has paramount importance for treatment and prognosis. The diagnostic approach should be multidisciplinary and include clinical examination, biochemical tests, imaging, and genetic analysis to assess the extent of the disease and its complications. ${ }^{36}{ }^{37}$

\section{Misdiagnosis}

Unfortunately, because many of the clinical signs of amyloidosis are non-specific, they are often misinterpreted. Fatigue may be misdiagnosed as functional or stress related. Purpura may be misdiagnosed as senile purpura or purpura simplex. Involvement of submandibular salivary glands may be interpreted as submandibular lymphadenopathy and consequent xerostomia as Sjögren syndrome. Increased sedimentation often leads to a diagnosis of polymyalgia rheumatica. ${ }^{35}$

\section{Non-invasive tests}

A diagnostic approach to patients with suspected cardiac amyloidosis might include the following non-invasive methods to help in establishing the diagnosis: electrocardiography, echocardiography including Doppler mode, chest radiography, magnetic resonance imaging, radionuclide imaging of radiolabelled amyloid $\mathrm{P}$ protein, protein electrophoresis to search for monoclonal immunoglobulins in serum and urine, abnormal transthyretin or amyloid A protein in serum, and genetic testing for suspected hereditary amyloid disorders. ${ }^{16}{ }^{18-20} 343839$

\section{"The diagnostic approach should be multidisciplinary and include clinical examination, biochemical tests, imaging, and genetic analysis to assess the extent of the disease and its complications"}

The first line non-invasive test for both the diagnosis and assessment of cardiac involvement is echocardiography with Doppler mode..$^{35}$ In the case of suspected primary amyloidosis, immunoanalysis of the serum and urine to detect monoclonal immunoglobulin light chains is the non-invasive diagnostic test of choice. ${ }^{1835}$ 
The serum hepatocyte growth factor concentration has been reported to be significantly higher in patients with both primary and secondary amyloidosis, ${ }^{40}$ but further multicentric studies are needed. Recently, the diagnostic potential of (trans,trans)-1-bromo-2,5-bis-(3-hydroxycarbonyl-4-hydroxy)styrylbenzene has been considered. This Congo red nontoxic derivative can bind to amyloid both in vivo and in vitro and it can be evaluated in scintigraphic studies. ${ }^{41}$

\section{Morphological diagnosis of amyloidosis in general}

Amyloid can be diagnosed and classified in any affected tissue specimen by means of special stains and biochemical analysis. The morphological diagnosis is of paramount importance and cannot be replaced by clinical, biochemical, or radiological procedures. Fat aspiration biopsy introduced by Westermark and Stenkvist in 1973 is the most common tool to diagnose systemic amyloidosis. ${ }^{42}$ Fat aspiration biopsy is simple, easy to perform and repeat, and bears a negligible risk of complications. However, fat aspiration biopsy is less sensitive than kidney and rectal biopsy. Moreover, the sample should not contain only fat droplets. Alternatively, if sufficient material is present, it can be used for further immunohistochemical, electron microscopical, and molecular analyses. ${ }^{43-47}$ Another standard procedure for the confirmation of the diagnosis of systemic amyloidosis is rectal biopsy, ${ }^{48-50}$ and amyloid is commonly diagnosed by renal biopsy. ${ }^{51}{ }^{52}$ Furthermore, sural nerve, skeletal muscle, and gastrointestinal biopsy samples other than rectal can also be used in the diagnosis of amyloidosis. ${ }^{44} 495354$ Table 3 provides a diagnostic algorithm for the diagnosis and classification of amyloidosis in biopsy samples.

\section{Biochemical analysis from biopsy material}

Both formalin fixed and fresh/frozen tissue samples can be used for the further biochemical analysis of amyloid. Reversed phase high performance liquid chromatography is the method of choice for the purification and analysis of amyloid proteins extracted from formalin fixed tissues. In contrast sodium dodecyl sulfate polyacrylamide gel electrophoresis based western blotting appears to be the better method for fresh tissue analysis..$^{55}$ Furthermore, the determination of chemical composition through amino acid sequencing or mass spectroscopy from formalin fixed specimens is available. ${ }^{56}$

\section{Diagnosis of cardiac amyloidosis}

Unfortunately, because of the diversity of symptoms, cardiac amyloidosis is diagnosed predominantly after death, ${ }^{57}$ although the tentative diagnosis of cardiac amyloidosis can easily be confirmed by myocardial biopsy.

\section{Endomyocardial biopsies}

Endomyocardial biopsy was found to be a safe and effective method for assessing cardiac amyloid involvement. ${ }^{58-61}$ According to American College of Cardiology/American Heart Association criteria, endomyocardial biopsy is recommended in patients with heart failure in whom an

Table 3 Diagnostic algorithm for biopsy samples to diagnose and classify amyloid

(1) Haematoxylin and eosin stain, Congo red polarisation

(2) Congo red fluorescence

If negative:

(3A) Serial sections of the whole sample (3B) Electron microscopy

(3AA) Haematoxylin and eosin stain, Congo red polarisation

(3AB) Congo red fluorescence

If positive:

(4) Immunohistochemical classification inflammatory or infiltrative disorder of the heart is suspected. $^{62}$ Fat aspiration biopsy is a possible alternative to endomyocardial biopsy in cases of primary amyloidosis. ${ }^{36}$ Another alternative is rectal biopsy, although this approach has a lower positivity, ranging from $58 \%$ to $80 \%$, and thus cannot substitute completely for endomyocardial biopsy..$^{5963}$ In cases with known amyloidosis, as demonstrated by a positive biopsy from extracardiac tissue with echocardiography and other signs indicating cardiac involvement, endomyocardial biopsy is not essential. ${ }^{57}{ }^{59}$ However, endomyocardial biopsy remains the method of choice to diagnose cardiac amyloidosis when non-invasive tests give equivocal results..$^{59} 6164$

In addition, immunohistochemical analysis to characterise amyloid protein is feasible. In most cases, the tissue obtained is sufficient for such an analysis. ${ }^{58}$ Endomyocardial biopsy also enables the degree of myocardial damage and cellular changes to be assessed. ${ }^{59} 61$

"Endomyocardial biopsy is recommended in patients with heart failure in whom an inflammatory or infiltrative disorder of the heart is suspected"

In a series of 454 endomyocardial biopsies, systemic amyloid was found in $7 \%$. The yield of endomyocardial biopsies is increased if at least four biopsy specimens are obtained. Importantly, cardiac involvement is interstitial, plentiful, and easily recognised compared with the almost exclusively vascular, mild, and focal pattern seen extracardially. ${ }^{59}$ Unfortunately, small amyloid deposits can be missed at light microscopy using Congo red staining. ${ }^{61}{ }^{65}$ Congo red fluorescence is recommended in all Congo red negative suspicious tissue samples. ${ }^{66}$ In such cases, electron microscopy is of paramount importance and positive results have been reported in Congo red negative cases. ${ }^{61}$

\section{Morphology}

Macroscopy

Amyloid is either indistinct or associated with a waxy cut surface. Localised forms can lead to organ enlargement and can imitate tumours.

At necropsy, the reaction with Gram's iodine followed by treatment with $10 \%$ sulfuric acid will show amyloid deposits as a blue/violet colour. Either fresh tissue or frozen sections can be used to demonstrate amyloid deposits. ${ }^{67}$

\section{Heart macroscopy}

Hearts infiltrated by amyloid are usually only moderately enlarged, weighing 400-850 g, although giant hearts of over $1000 \mathrm{~g}$ have also been described. ${ }^{30} 3368$ Interestingly, the mean cardiac weight in senile involvement was significantly higher than that seen in subjects with primary (even fatal) involvement. ${ }^{33}$ Most infiltrated hearts are firm, rubbery, and non-compliant, mimicking hypertrophic cardiomyopathythat is, the walls of heart chambers are thickened, but the ventricular lumina are not dilated. About one third of hearts have dilated chambers imitating congestive cardiomyopathy. Importantly, about $15 \%$ of hearts show no macroscopically visible changes. ${ }^{6970}$ In the senile form, atrial deposits are grossly discernible as bead-like, semitranslucent nodules (fig lA). ${ }^{30} 70$

\section{Light microscopy and special stains General pattern and stains}

At light microscopy, all forms of amyloid deposits are amorphous and homogenous, with pale eosinophilic areas, when stained with haematoxylin and eosin (fig 1B, C).

Since the 19th century, amyloid deposits have been known to stain metachromatically if aniline dyes such as methyl or 



Figure 1 Example of a heart with amyloidosis. (A) Macroscopic view showing nodules with amyloid (arrows). (B) Microscopic view showing eosinophilic areas containing amyloid (asterisks); original magnification, $\times 100$. (C) Microscopic view showing eosinophilic bands, containing amyloid, around individual cardiomyocytes (arrows); original magnification, $\times 100$. (D) Microscopic view (same figure as C) showing apple green birefringance under polarised light; original magnification, $\times 100$. (E) An intramyocardial artery showing Congo red stained amyloid (arrow); original magnification, $\times 400$. (F) An intramyocardial artery (same figure as E) showing apple green birefringance under polarised light; original magnification, $\times 400$. (G) Amyloidosis is characterised by the deposition of fine fibrillar material (asterisk) in and around cardiomyocytes (arrow); original magnification, $\times 10$ 000. (H) Amyloidosis is characterised by the deposition of fine fibrillar material (asterisk) around small vessels; arrow, endothelial cell; original magnification, $\times 15000$.

crystal violet are used. At present, Congo red is the standard staining method. Congo red stained amyloid has an orange or red colour on light microscopy and has apple green birefringence under polarised light (fig $1 \mathrm{D}-\mathrm{F}$ ). However, Congo red is not specific, because it also stains eosinophil granules, enterochromaffin granules, Paneth cell granules, elastic fibres, collagen, and foreign materials such as chitin, fungal constituents, and plant components. Certain pitfalls can be avoided by alkaline Congo red modification. ${ }^{66} 71-76$
Most of the other stains available are not recommended to be used alone and are listed with decreasing specificity and sensitivity: Sirius red, thioflavine $\mathrm{T}$, toluidine blue, $p$-dimethylaminobenzaldehyde-nitrite, alcian blue, and crystal violet. ${ }^{67} 74^{75}$ Alternatively, a panel of special stains has been recommended to increase the sensitivity in certain cases because of possible staining variability. ${ }^{76}$ Importantly, prolonged formalin fixation of amyloid tissue may abolish or lessen its staining reactions. Some authors stated Sirius red 
as superior in cardiac amyloidosis, particularly for identifying very small deposits in the isolated atrial form. ${ }^{29}$

\section{Cardiac involvement pattern}

The degree of involvement of different parts of the heartendocardium, myocardium, pericardium, valves, coronary arteries, and veins-is not uniform in the different forms of amyloidosis. ${ }^{30} 5859$ However, amyloid patterns are of limited value in the diagnosis in individual patients. ${ }^{58}$ Perifibrous/ pericellular is the most common pattern seen, and nodular and mixed patterns have also been described. ${ }^{175859} 70$ Interestingly, atrophy of the surrounding myocytes and fibrosis of the conduction system have been noted in relation to amyloid deposition. ${ }^{77} 78$ The myocytes often reveal perinuclear vacuolation, ${ }^{57}$ although this is a non-specific feature also found in hypertrophy related to increased glycogen storage. Amyloid deposits in the vessel wall are predominantly segmentally distributed and cause luminal narrowing. ${ }^{57}$

\section{Immunohistochemistry}

The immunohistochemical classification of amyloid deposits is a useful tool with increasing importance in amyloid diagnosis, and a large number of anti-amyloid fibril protein antibodies are commercially available. However, the increasing number of amyloid fibrillar proteins identified may be demanding in routine practice. The following spectrum of fibrillar proteins is recommended to test for the most common systemic amyloidosis: amyloid A, amyloid of apolipoprotein A-1, amyloid of fibrinogen $\alpha$ chain, amyloid of light chains, amyloid of lysozyme, amyloid of transthyretin, and amyloid of $\beta 2$ microglobulin origin. Table 4 lists a differential diagnostic panel of antibodies to be used in heart and vessel amyloid assessment. ${ }^{47-83}$ Recently, an immunogold technique that enables typing of amyloid in difficult clinical cases was reported. ${ }^{84}$

\begin{abstract}
"The immunohistochemical classification of amyloid deposits is a useful tool with increasing importance in amyloid diagnosis, and a large number of anti-amyloid fibril protein antibodies are commercially available"
\end{abstract}

In routine histopathology practice we face both false negativity and positivity of the specimens. The main reason for false positivity is when amyloid fibril proteins originate from serum proteins, which are then detected in the tissues although they are not related to amyloid. In contrast, the cleavage products of amyloid fibrillar proteins lose their epitopes or differ greatly from the precursor protein structure. Immunoelectron microscopy is an additional useful tool that can easily distinguish contaminating labelled protein structures. ${ }^{47} 8082$

Table 4 Commercially available antibodies against amyloid protein fibrils in general/cardiovascular amyloidosis diagnostics

\begin{tabular}{lll}
\hline Antibody & Clonality/clone & Distributor \\
\hline$\kappa$ Light chain & Polyclonal & $\begin{array}{l}\text { Dako, Glostrup, } \\
\text { Denmark }\end{array}$ \\
$\lambda$ Light chain & Polyclonal & Dako \\
AA Amyloid & Monoclonal/mcl & Dako \\
$\beta 2$ Microglobulin & Polyclonal & Dako \\
Atrial natriuretic & Polyclonal & Biogenesis, Poole, \\
peptide & & Dorset, UK \\
Transthyretin & Polyclonal & Dako \\
\hline
\end{tabular}

\section{Electron microscopy}

\section{General ultrastructure}

Ultrastructurally, amyloid consists of a loose meshwork of 7-10 nm rigid, non-branching, hollow fibrils of indeterminate length. The fibrils measure from 30 to more than $1000 \mathrm{~nm}$ in length. These fibrils are usually found in extracellular spaces and aggregate in a crossed $\beta$ pleated sheet conformation. ${ }^{128586}$

\section{Cardiac ultrastructure}

In the myocardium, pericellular encasement non-branching fibrils are found. Fibrils are adjacent to the basement membrane of myocytes, some of which can be completely surrounded by fibrillous material (fig $\mathrm{lG}, \mathrm{H}$ ). The amyloid fibrils are in close proximity to the basement membrane of the myocytes. Furthermore, the deposition of amyloid is associated with a focal increase of mitochondria. ${ }^{57}{ }^{87}$ Electron microscopy can detect amyloid when histochemical stains such as Congo red are still negative.

\section{CARDIOVASCULAR AMYLOIDOSIS AS A PART OF PRIMARY AMYLOIDOSIS}

In primary amyloidosis, clonal plasma cells secrete monoclonal immunoglobulin light chains, which are deposited predominantly in the kidney, heart, and nerves. ${ }^{11} 18$ Symptomatic cardiac involvement is present in a quarter to half of patients with primary amyloidosis and is the major prognostic factor. ${ }^{18}{ }^{34}$ Importantly, a cardiac cause of death is the most common amyloid related death in primary amyloidosis, and is seen in $40 \%$ of patients in the form either of congestive heart failure or arrhythmia. ${ }^{336488} 89$ Congestive heart failure is the most frequent cardiovascular manifestation. Conduction system abnormalities and heart blocks are the second most frequent complications. ${ }^{33} 3488$ Stenoses and obstructions in the intramural coronary arteries by amyloid deposits can lead to ischaemic disease, which differs in prognosis. Interestingly, epicardial coronary artery involvement and interstitial myocardial involvement were absent or mild in these cases..$^{90-92}$ In addition, non-sclerotic valves showed amyloid deposits in primary amyloidosis. ${ }^{93}$ Pericardial effusion is a common symptom. However, constrictive pericarditis and cardiac tamponade resulting from amyloid deposits are unique. ${ }^{94} 95$ Orthostatic hypotension caused by amyloid deposits in nerves and ganglia was also revealed. ${ }^{88}$ Uniquely, cardiac denervation was described in primary amyloidosis, with no other cardiac symptoms ${ }^{96}$ In general, cardiac involvement in the absence of other organ deposits is rare. ${ }^{34}$

Systemic vascular involvement often leads to obstruction and consequent ischaemia. ${ }^{17}{ }^{97} \mathrm{In}$ fact, vascular involvement is very common (around 90\%), affecting medium to large arterioles and small arteries. Amyloid is then deposited in the media and adventitia, thereby thickening the wall. Interstitial fibrosis and degeneration of myocytes as a result of ischaemia was seen in the vicinity of these vessels. ${ }^{20} 3358778398$

\section{SECONDARY AMYLOIDOSIS}

With the decrease of chronic infectious diseases, such as tuberculosis and osteomyelitis in the developed world, secondary amyloidosis has become rare and is found mainly in association with diseases such as rheumatoid arthritis and inflammatory bowel disease. ${ }^{16} \mathrm{~A}$ tumour related form is also diagnosed and recently haemodialysis related amyloidosis was described. ${ }^{83}{ }^{99}$ Amyloid is formed from serum amyloid A (SAA), an acute phase protein produced in response to inflammation. Several forms of SAA have been identified in human plasma. SAAl predominates in the formation of amyloid A deposits. ${ }^{100}{ }^{101}$ The major constituent protein in haemodialysis related amyloidosis is $\beta_{2}$ microglobulin. ${ }^{99}$ 
Cardiac involvement may occur; however, significant deposition of amyloid in the heart is unusual and is rarely the cause of death. ${ }^{17} 19102$ Although myocardial infiltration is unusual, there have been case reports of extensive cardiac involvement, even with cardiac failure and arrhythmia, in secondary amyloidosis in such diseases as juvenile rheumatoid arthritis, sarcoid, psoriatic spondyloarthropathy, and multifocal neurone neuropathy. ${ }^{103-106}$ Vascular involvement is less frequent, mostly involving intramyocardial small vessels. In contrast, in $\beta_{2}$ microglobulin amyloidosis, only vascular and endocardial involvement was described. ${ }^{20} 8398104$ Involvement of the conduction system was described accompanying juvenile rheumatoid arthritis and psoriatic spondyloarthropathy. ${ }^{104}{ }^{105}$ Amyloid deposits were also found in post rheumatic sclerotic valves. ${ }^{107} 108$

\section{AGE RELATED AMYLOIDOSIS}

Age related amyloidosis is either isolated atrial or systemic senile amyloidosis (formerly designated senile cardiac amyloidosis). In addition, transthyretin isoleucine 122 amyloidosis is sometimes thought to be age related, despite it being an autosomal recessive disease. ${ }^{64}$

\section{Isolated atrial amyloidosis}

Isolated atrial amyloidosis (IAA) is a common postmortem finding in the elderly and has been reported to occur in as many as $90 \%$ of those $\geqslant 90$ years of age. ${ }^{26} 2829$ IAA first appears in the third decade and its prevalence increases linearly by $15-20 \%$ with each subsequent decade. ${ }^{28} 29109$ Interestingly, the prevalence of IAA was found to be significantly higher in the chronic rheumatic heart and in mitral valve disease. ${ }^{81}{ }^{109}$ Women have a higher prevalence of IAA. $^{29} 81$

Atrial natriuretic peptide (ANF) is the major protein subunit of the amyloid fibril in IAA. ${ }^{110}$ IAA can theoretically be found at any site expressing ANF; however, only atria are targeted in IAA.

\section{"Isolated atrial amyloidosis is a common postmortem finding in the elderly and has been reported to occur in as many as $90 \%$ of those $\geqslant 90$ years of age ${ }^{\prime \prime}$}

Although the clinical relevance of IAA is not clear, patients with IAA are more likely to develop atrial fibrillation. ${ }^{2681}$

Left atrial deposits are more pronounced. In addition, deposits are usually found in the auricles, predominantly beneath the endocardium. Microscopically, very thin deposits occur along the sarcolemma of atrial myocytes, with a tendency to coat them. Small intracellular deposits are frequently present in these cells. Associated myocyte hypertrophy has been described. Of note, in Rocken's study, IAA amyloid deposits correlated inversely with the degree of interstitial fibrosis. ${ }^{81}$ Very small vessels are often involved. ${ }^{25} 27^{109}$ Amyloid deposits were found to be 100\% positive for ANP and four of 40 cases showed transthyretin immunopositivity ${ }^{81}$ However; there is no correlation between the degree of IAA and the presence of systemic senile amyloidosis (SSA) ${ }^{29}$

\section{Systemic senile amyloidosis}

The prevalence of SSA increases with each decade above the age of 60 , occurring in $25 \%$ of people over the age of 80 years, and thus is the most common form of systemic amyloidosis. ${ }^{25-28}$ However, symptomatic senile cardiac amyloidosis was reported in a patient as young as 57 years. ${ }^{89}$ The major constituent of the amyloid fibrils in SSA is derived from normal transthyretin (TTR), previously known as prealbumin. ${ }^{28}$ TTR is also the major precursor for several heredofamilial forms of amyloidosis and, to date, more than 40 point mutations have been found..$^{27}{ }^{28}$ However, TTR mutation is not required for the deposition of senile systemic amyloid and TTR in SSA has a normal primary structure..$^{28}$

Although initially cardiac involvement was thought to be an incidental finding in SSA, its extent is similar to that found in primary amyloidosis, although it does not carry the same grave prognosis. ${ }^{25} 5870111$ Only a small proportion of patients develop cardiomegaly with heart failure and/or arrhythmia. ${ }^{27}$

The extracardiac involvement is limited to the aorta, pulmonary vessels, and pulmonary alveolar septa. ${ }^{25}$ In the heart, both atria and ventricles are involved, and the small to medium sized vessels are involved to a lesser extent (4-27\%). Microscopically, large diffuse or multifocal, predominantly nodular, deposits are present between muscle bundles. Deposits become less homogeneous in density and more fibrillar as the deposits increase in size. Adjacent cells are often atrophied. In contrast to primary amyloidosis, the conduction system is not affected. ${ }^{20} 255870112$

\section{HEREDITARY AMYLOIDOSIS}

Familial amyloidosis occurs throughout the world and in all ethnic groups. It encompasses an extremely broad spectrum of clinical manifestations but is dominated by peripheral neuropathy, renal failure, intracranial haemorrhage as a result of cerebral amyloid angiopathy, and ocular deposition. ${ }^{21}{ }^{24}$ Cardiopathic forms are characterised by severe heart failure and arrhythmias. ${ }^{2165}{ }^{113-116}$ Symptomatic valvular amyloid involvement has also been reported. ${ }^{117}$

The most common form is caused by mutant TTR. Although neurological symptoms are predominant, several variants with cardiac involvement have been described. $^{2165114-116118119}$ In addition, a form caused by a point mutation in codon 122 of the TTR gene, which results in substitution of isoleucine for valine during TTR translation, was found in $3.9 \%$ of the Afro-American population, with a 7.5 fold greater risk of developing cardiac amyloidosis in heterozygous subjects. ${ }^{120}$ Interestingly, patients with familial amyloid polyneuropathy in Japan revealed wild-type TTR in their hearts. ${ }^{121}$

\section{VALVULAR AMYLOID INVOLVEMENT}

Microscopic amyloid deposits were described in $15.5-88 \%$ of sclerotic valves with simultaneous occurrence of hyalinisation and calcification. ${ }^{103} 107108122$ Biochemical and immunohistochemical assessment failed to identify all known amyloidosis related proteins in valvular deposits. ${ }^{107} 123$ Interestingly, an association between valvular amyloid deposits and old thrombotic material was proposed. ${ }^{124}$ Furthermore, amyloid was found in porcine bioprosthetic cardiac valves after explantation following longterm implantation. ${ }^{125}$

\section{AMYLOID INVOLVEMENT OF VESSELS Senile aortic amyloid}

Occurring in nearly all people over 50 years of age, aortic amyloid appears to be the most common form of localised amyloid. Biochemically, aortic amyloid is distinct either from ANP present in IAA or from TTR in SSA. ${ }^{126}{ }^{127}$ Recently, the lactadherin derived protein, medin, was purified from medial amyloid deposits in aortas and temporal arteries, ${ }^{128} 129$ whereas intimal amyloid is derived from apolipoprotein A-I. ${ }^{130} 131$ Serum amyloid A isotypes were detected in atherosclerotic lesions. ${ }^{132}$

\footnotetext{
"Occurring in nearly all people over 50 years of age, aortic amyloid appears to be the most common form of localised amyloid"
} 
Three different forms involving the media, intima, and adventitia have been described so far. The most common form is in the media, followed by intimal and adventitial deposition. The clinical relevance is not clear yet. No casual relation between aortic amyloid and hypertension or dissecting aneurysm was observed. The thoracic aorta is predominantly involved in the medial form: nodules and thin streaks in the inner half of the media are mostly in the proximity of elastin fibres. Intimal amyloid is associated with atheromatous lesions and appears as irregular lumps. Adventitial amyloid is either in the connective tissue or in the walls of the vasa vasorum. ${ }^{27} 126129$

\section{Other forms of vascular amyloidosis}

Senile amyloid angiopathy has been described in a variety of vessels. Its biochemical characteristics remain unknown, but similarities between aortic medial amyloid and medial amyloid of the common carotid and temporal arteries were reported. ${ }^{27} 129131$ Senile vascular amyloidosis derived from the $\mathrm{N}$-terminus of apolipoprotein A-I reported in dogs has yet to be documented in humans. ${ }^{27}{ }^{133}$ Interestingly, amyloid involvement was greater in the veins than in the arteries in senescence accelerated mice. ${ }^{134}$

\section{TREATMENT}

The therapeutic approach depends on the type of amyloidosis and the stage of the disease, so the precise diagnosis is of principal importance. The treatment of amyloidosis is specifically directed at the amyloidogenic process, and supportive treatments directed to consequent organ dysfunctions. ${ }^{18}$

Supportive treatment of cardiac failure includes diuretics, whereas calcium channel blockers, $\beta$ blockers, and digoxin are contraindicated in cardiac amyloidosis. ${ }^{16}$ Patients with arrhythmia may benefit from a pacemaker. ${ }^{16}$

In primary amyloidosis, chemotherapy regimens of melphalan and prednisone have been used for decades and are the most successful. Alternative drugs under consideration and in trials are $4^{\prime}$-iodo-4'-deoxydoxorubicin, vincristine, dexamethasone, and $\alpha$ interferon. ${ }^{16}{ }^{18}{ }^{135}$ Cardiac transplantation with supportive chemotherapy is under consideration, ${ }^{16}{ }^{136}$ and stem cell transplantation is another treatment option. ${ }^{135} 137$

Secondary amyloidosis requires aggressive treatment of the underlying inflammatory or neoplastic process.

Currently, no definitive treatment is available in nonhereditary, age related amyloidosis; however, patients may benefit from supportive treatment, including a pacemaker. ${ }^{16}{ }^{64}$

To date, no effective treatment has been reported for the most common hereditary amyloidosis, TTR amyloidosis, apart from liver transplantation. However, the onset of cardiomyopathy can be prevented if liver transplantation is carried out before cardiac involvement. ${ }^{65}$ Successful combined heart-liver and liver-kidney transplantation was reported for hereditary TTR and apolipoprotein A-I amyloidosis, respectively. ${ }^{138} 139$

Future perspectives include treatments based on precursor stabilisation (transthyretin), prevention of formation by crosslinking, elimination of the synthesising cells (light chains), and immunisation to induce host mediated reaction (light chains). ${ }^{37} 140141$

\section{PROGNOSIS}

The prognosis varies according to the type of amyloidosis, the stage of the disease, and the age of the patient at the time of diagnosis. Primary amyloidosis has the worst prognosis, which is exacerbated by multisystem involvement and cardiac involvement in particular. ${ }^{142}$ Histologically, the worst
Take home messages

- The cardiovascular system is often affected by amyloidosis - the extracellular deposition and accumulation of insoluble fibrillar proteins

- The heart is targeted most frequently in the primary and age related forms of amyloidosis, less frequently in transthyretin familial amyloidosis, and only rarely in secondary forms of amyloidosis

- Cardiac infiltration results in cardiac symptoms dominated by congestive heart failure, arrhythmias, and cardiomyopathy

- The diagnosis of amyloidosis requires a multidisciplinary approach, including clinical examination, biochemical tests, imaging, and genetic analysis, and should be confirmed by Congo red staining in polarised light of a tissue sample

- In addition, immunohistochemistry should be used to define the protein fibril type because it is of diagnostic, prognostic, and therapeutic importance

prognosis is connected with the presence of nodular deposits, thick perimyocytic layers of amyloid, and small myocyte diameters in endomyocardial biopsy. ${ }^{61}$ The overall median survival after diagnosis is less than two years in most. In secondary amyloidosis, the underlying chronic disease affects the prognosis, and hereditary amyloidoses vary in prognosis according to the specific mutation. ${ }^{16}{ }^{18}{ }^{34}$ In addition, heart rate variability assessed by Holter monitoring was found to be a possible predictor of mortality in patients with both primary and secondary amyloidosis involving the heart. ${ }^{143}$ Echocardiography should be a routine part of the assessment of cardiac involvement and predicting prognosis. ${ }^{35}$

\section{CONCLUSIONS}

Amyloidosis often affects the cardiovascular system. The heart is usually infiltrated by amyloid fibrils in primary amyloidosis and age related forms of amyloidosis, less commonly in transthyretin familial amyloidosis, and rarely in secondary amyloidosis. Cardiac infiltration results in cardiac symptoms dominated by congestive heart failure and arrhythmias. The diagnosis of amyloidosis requires tissue sample confirmation. Congo red staining in polarised light is the method of choice at the present. However, the pathologist should not only make the generic diagnosis of the presence of amyloid, but should also determine the protein fibril type by means of immunohistochemistry, because it is of diagnostic, prognostic, and therapeutic importance.

\section{ACKNOWLEDGEMENTS}

Dr Kholová was a PhD student of the Marie Curie Training Site of the European Community (No. HPMT-2000-114) at the ICaR-VU. Dr Niessen is a recipient of the Dr E Dekker program of the Netherlands Heart Foundation (D99025). The project was supported by grant IGA Ministry of Health CR No. 7592-3.

\section{Authors' affiliations}

I Kholová, , H W M Niessen, Department of Pathology, Vrije Universiteit Medical Centre, De Boelelaan 1117, 1007 MB Amsterdam, The Netherlands

*Present address: A.I Virtanen Institute for Molecular Sciences, University of Kuopio, Kuopio, Finland 


\section{REFERENCES}

1 Glenner GG. Amyloid deposits and amyloidosis. The beta-fibrilloses. N Engl J Med 1980;302:1283-92.

2 Glenner GG. Amyloid deposits and amyloidosis. The beta-fibrilloses. N Engl J Med 1980;302:1333-43.

3 Merlini G, Bellotti V. Molecular mechanisms of amyloidosis. N Engl J Med 2003;349:583-96.

4 Westermark P, Araki S, Benson MD, et al. Nomenclature of amyloid fibril proteins. Part 1. Amyloid 1999;6:63-6.

5 Westermark P, Benson MD, Buxbaum JN et al. Amyloid fibril protein nomenclature-2002. Amyloid 2002;9:197-200.

6 WHO-IUIS Nomenclature Sub-Committee. Nomenclature of amyloid and amyloidosis. Bull World Health Organ 1993;71:105-12.

7 Husby G. Stenstad T, Magnus JH, et al. Interaction between circulating amyloid fibril protein precursors and extracellular tissue matrix components in the pathogenesis of systemic amyloidosis. Clin Immunol Immunopathol 1994;70:2-9.

8 Kawahara E, Shiroo M, Nakanishi I, et al. The role of fibronectin in the development of experimental amyloidosis: evidence of immunohistochemical codistribution and binding property with serum amyloid protein $\mathrm{A}$. Am J Pathol 1989;134:1305-14.

9 Lyon AW, Narindrasorasak S, Young ID, et al. Co-deposition of basement membrane components during the induction of murine splenic AA amyloid. Lab Invest 1991;64:785-90.

10 Röcken C, Shakespeare A. Pathology, diagnosis and pathogenesis of AA amyloidosis. Virchows Arch 2002;440:111-22.

11 Buxbaum JN. Diseases of protein conformation: what do in vitro experiments tell us about in vivo diseases. Trends Biochem Sci 2003;28:585-92.

12 Ando Y, Suhr O, El-Salhy M. Oxidative stress and amyloidosis. Histol Histopathol 1998;13:845-50

13 Brenner DA, Jain M, Pimentel DR, et al. Human amyloidogenic chains directly impair cardiomyocyte function through an increase in cellular oxidant stress. Circ Res 2004:94:1008-10.

14 Andersson K, Olofsson A, Nielsen EH, et al. Only amyloidogenic intermediates of transthyretin induce apoptosis. Biochem Biophys Res Commun 2002;294:309-14.

15 Loo DT, Agata C, Pike CJ. Apoptosis is induced by $\beta$-amyloid in cultured nervous system neurons. Proc Natl Acad Sci U S A 1993:90:7951-5.

16 Falk RH, Comenzo RL, Skinner M. The systemic amyloidosis. N Engl J Med 1997; 337:898-909.

17 Kyle RA, Bayrd ED. Amyloidosis: a review of 236 cases. Medicine 1975;54:271-91.

18 Pascali E. Diagnosis and treatment of primary amyloidosis. Crit Rev Oncol Hematol 1995; 19:149-81.

19 Browning MJ, Banks RA, Tribe CR, et al. Ten years experience of an amyloid clinic-a clinicopathologic survey. Q J Med 1985;54:213-27.

20 Kingman A, Pereira NL. Cardiac amyloidosis. J S C Med Assoc 2001;97:201-6.

21 Varga J, Wohlgethan JR. The clinical and biochemical spectrum of hereditary amyloidosis. Semin Arthritis Rheum 1988;18:14-28.

22 Sohar E, Pras M. Heller J, et al. Genetics of familial Mediterranean fever. Arch Intern Med 1961;107:529-38.

23 Gorevic PD, Rodrigues MM. Ocular amyloidosis. Am J Ophthalmol 1994; 117:529-32.

24 Thomas PK. Genetic factors in amyloidosis. J Med Genet 1975;12:317-26.

25 Cornwell GG III, Westermark P. Senile amyloidosis: a protean manifestation of the aging process. J Clin Pathol 1980;33:1 1 146-52.

26 Cornwell GG III, Murdoch WL, Kyle RA, et al. Frequency and distribution of senile cardiovascular amyloid: a clinicopathologic correlation. Am J Med 1983;75:618-23.

27 Cornwell GG III, Johnson KH, Westermark P. The age related amyloids: a growing family of unique biochemical substances. J Clin Pathol 1995:48:984-9

28 Westermark $\mathbf{P}$, Sletten $\mathrm{K}$, Johanson $\mathrm{B}$, et al. Fibril in senile systemic amyloidosis is derived from normal transthyretin. Proc Natl Acad Sci U S A 1990;87:2843-5.

29 Steiner I. The prevalence of isolated atrial amyloid. J Pathol 1987:153:395-8.

30 Lie JT. Pathology of amyloidosis and amyloid heart disease. Appl Pathol 1984;2:341-56.

31 Reisinger J, Dubrey SW, Lavalley $M$, et al. Electrophysiological abnormalities in AL (primary) amyloidosis with cardiac involvement. J Am Coll Cardiol 1997:30:1046-51.

32 Cantwell R, Aviles R, Bjornsson J. Cardiac amyloidosis presenting with elevations of cardiac troponin I and angina pectoris. Clin Cardio 2002;25:33-7.

33 Wright JR, Calkins E. Clinical-pathologic differentiation of common amyloid syndromes. Medicine (Baltimore) 1981:60:429-48.

34 Dubrey SW, Cha K, Anderson J, et al. The clinical features of immunoglobulin light-chain (L) amyloidosis with heart involvement. Q J Med 1998:91:141-57.

35 Gertz MA, Lacy MQ, Dispenzieri A. Amyloidosis. Hematol Oncol Clin North Am 1999:13:1211-33.

$36 \mathrm{O}^{\prime}$ Hara CJ, Falk RH. The diagnosis and typing of cardiac amyloidosis. Amyloid 2003;10:127-9.

37 Buxbaum JN. The systemic amyloidoses. Curr Opin Rheumatol 2004; 16:67-75

38 Klein AL, Oh JK, Miller FA, et al. Two-dimensional and Doppler echocardiographic assessment of infiltrative cardiomyopathy. J Am Soc Echocardiogr 1988;1:48-59.
39 Fattori $R$, Rocchi $G$, Celleti $F$, et al Contribution of magnetic resonance imaging in the differential diagnosis of cardiac amyloidosis and symmetric hypertrophic cardiomyopathy. Am J Heart 1998;136:824-30.

40 Shikano M, Kushimoto $\mathrm{H}$, Hasegawa $\mathrm{H}$, et al. Usefulness of serum hepatocyte growth factor for the diagnosis of amyloidosis. Intern Med 2000:39:715-19.

41 Ando $\mathrm{Y}$, Haraoka K, Terazaki H, et al. A novel tool for detecting amyloid deposits in systemic amyloidosis in vitro and in vivo. Lab Invest 2003;83:1751-9.

42 Westermark P, Stenkvist P. A new method for the diagnosis of systemic amyloidosis. Arch Intern Med 1973;132:522-3.

43 Gertz MA. Diagnosing primary amyloidosis. Mayo Clin Proc 2002;77:1278-9.

44 Kuroda T, Tanabe N, Sakatsume M, et al. Comparison of gastroduodenal, renal and abdominal fat biopsies for diagnosing amyloidosis in rheumatoid arthritis. Clin Rheumatol 2002;21:123-8.

45 Masouye I. Diagnostic screening of systemic amyloidosis by abdominal fat aspiration: an analysis of 100 cases. Am J Dermatopathol 1997;19:41-5.

46 Orfila C, Giraud P, Modesto A, et al. Abdominal fat tissue aspirate in human amyloidosis: light, electron, and immunofluorescence microscopic studies. Hum Pathol 1986;17:366-9.

47 Röcken C, Sletten K. Amyloid in surgical pathology. Virchows Arch 2003;443:3-16

48 Gafni J, Sohar E. Rectal biopsy for the diagnosis of amyloidosis. Am J Med Sci 1960:240:332-6.

49 Fatihi E, Ramdani B, Fadel H, et al. Prevalence of subcutaneous, labial, and rectal amyloidosis in patients with renal amyloidosis. Nephrologie 2000;21:19-21.

50 Kyle RA, Spencer RJ, Dahlin DC. Value of rectal biopsy in the diagnosis of primary systemic amyloidosis. Am J Med Sci 1966;251:501-6.

51 Gertz MA, Lacy MQ, Dispenzieri A. Immunoglobulin light chain amyloidosis and the kidney. Kidney Int 2002;61:1-9.

52 Schena FP, Pannarale G, Carbonara MC. Clinical and therapeutic aspects of renal amyloidosis. Nephrol Dial Transplant 1996;11(suppl 9):63-8.

53 Rajani B, Rajani V, Prayson RA. Peripheral nerve amyloidosis in sural nerve biopsies - a clinicopathologic analysis of 13 cases. Arch Pathol Lab Med 2000;124:114-18.

54 Prayson RA. Amyloid myopathy: clinicopathologic study of 16 cases. Hum Pathol 1998;29:463-8.

55 Kaplan B, Shtrasburg S, Pras M. Micropurification techniques in the analysis of amyloid proteins. J Clin Pathol 2003;56:86-90.

56 Murphy CL, Eulitz M, Hrncic R, et al. Chemical typing of amyloid protein contained in formalin-fixed paraffin-embedded biopsy specimens. Am J Clin Pathol 2001;116:135-42

57 Frenzel H, Schwartzkopff, Kuhn H, et al. Cardiac amyloid deposits in endomyocardial biopsies. Light microscopic, ultrastructural, and immunohistochemical studies. Am J Clin Pathol 1986;85:674-80.

58 Crotty TB, Li C-Y, Edwards WD, et al. Amyloidosis and endomyocardial biopsy: correlation and extent and pattern of deposition with amyloid immunophenotype in 100 cases. Cardiovasc Pathol 1995;4:39-42.

59 Pellikka PA, Holmes DR, Edwards WD, et al. Endomyocardial biopsy in 30 patients with primary amyloidosis and suspected cardiac involvement. Arch Intern Med 1988;148:662-6.

60 Olson L, Gertz MA, Edwards WD, et al. Senile cardiac amyloidosis with myocardial dysfunction: diagnosis by endomyocardial biopsy and immunohistochemistry. N Engl J Med 1987;317:738-42.

61 Arbustini E, Merlini G, Gavazzi A, et al. Cardiac immunocyłe-derived (AL) amyloidosis: an endomyocardial biopsy study in 11 patients. Am Heart $J$ 1995; 130:528-36

62 Hunt SA, Baker DW, Chin MH, et al. ACC/AHA guidelines for the evaluation and management of chronic heart failure in the adult: executive summary: a report of the American College of Cardiology/American Heart Association task force on practice guidelines (committee to revise the 1995 guidelines for the evaluation and management of heart failure). Circulation 2001;104:2996-3007.

63 Scully RE, Mark EJ, McNeely BU. Case records of the Massachusetts General Hospital. Case 30-1982. N Engl J Med 1982;307:298-303.

64 McCarthy RE, Kasper EK. A review of the amyloidoses that infiltrate the heart. Clin Cardiol 1998;21:547-52.

65 Suhr OB, Hastrup Svendsen I, Andersson R, et al. Hereditary transthyretin amyloidosis from a Scandinavian perspective. J Intern Med 2003;254:225-35.

66 Linke RP. Highly sensitive diagnosis of amyloid and various amyloid syndromes using Congo red fluorescence. Virchows Arch 2000;436:439-48.

67 Bancroft JD, Cook HC. Amyloid. In: Manual of histological techniques, 1st ed. Edinburgh: Churchill Livingstone, 1984:87-99.

68 Eliot RS, McGee HJ, Blount SG Jr. Cardiac amyloidosis. Circulation 1961;23:613-22.

69 Roberts WC, Waller BF. Cardiac amyloidosis causing cardiac dysfunction: analysis of 54 necropsy patients. Am J Cardiol 1983:52:137-46.

70 Smith TJ, Kyle RA, Lie JT. Clinical significance of histopathologic patterns of cardiac amyloidosis. Mayo Clin Proc 1984;59:547-55.

71 Bennhold H. Eine spezifische Amyloidfärburg mit Kongorot. Munch Med Wochenschr 1920;69:1537-49.

72 Pearse AGE. Amyloids: the $\beta$-fibrilloses. In: Histochemistry: theoretical and applied, Vol. II, 4 ed. Boston: Little Brown and Co, 1985:576-82.

73 Wolman M, Bubis JJ. The cause of the green polarization color of amyloid stained with Congo red. Histochemie 1965;4:351-9.

74 Puchtler $\mathrm{H}$, Waldrop FS, Meloan SN. A review of light, polarization and fluorescence microscopic methods for amyloid. Appl Pathol 1985;3:5-17.

75 Westermark GP, Johnson KH, Westermark P. Staining methods for identification of amyloid tissue. Methods Enzymol 1999:309:3-25. 
76 Nippoldt TB, Edwards WD, Holmes DR Jr, et al. Right ventricular endomyocardial biopsy: clinicopathologic correlates in 100 consecutive patients. Mayo Clin Proc 1982;57:407-18.

77 Smith RR, Hutchins GM. Ischemic heart disease secondary to amyloidosis of intramyocardial arteries. Am J Cardiol 1979;44:413-17.

78 Ridolfi BL, Bulkley BH, Hutchins GM. The conduction system in cardiac amyloidosis: clinical and pathologic features of 23 patients. Am J Med 1977;62:677-86.

79 Kisilevsky R. Amyloid and amyloidoses: differences, common themes, and practical considerations. Mod Pathol 1991;4:514-18.

80 Röcken C, Schwotzer E, Linke RP, et al. The classification of amyloid deposits in clinicopathological practice. Histopathology 1996;29:325-35.

81 Röcken C, Peters B, Juenemann G, et al. Atrial amyloidosis. An arrhythmogenic substrate for persistent atrial fibrillation. Circulation 2002; 106:2091-7

82 Arbustini E, Morbini P, Verga L, et al. Light and electron microscopy immunohistochemical characterization of amyloid deposits. Amyloid 1997;4:157-70.

83 Strege RJ, Saeger W, Linke RP. Diagnosis and immunohistochemical classification of systemic amyloidoses. Report of 43 cases in an unselected autopsy series. Virchows Arch 1998:433:19-27.

84 Arbustini $E$, Verga L, Concorde $M$, et al. Electron and immuno-electro microscopy of abdominal fat identifies and characterizes amyloid fibrils in suspected cardiac amyloidosis. Amyloid 2002;9:108-14

85 Cohen AS, Calkins E. Electron microscopic observations on fibrous component in amyloid of diverse origin. Nature 1959;183:1202-3.

86 Stevens FJ, Myatt EA, Chang CH, et al. A molecular model for self-assembly of amyloid fibrils: immunoglobulin light chains. Biochemistry 1995;34:10697-702.

87 Mudhar HS, Wagner BE, Suvarna SK. Electron microscopy of myocardial tissue. A nine year review. J Clin Pathol 2001;54:321-5.

88 Kyle RA, Greipp PR. Amyloidosis (AL): clinical and laboratory features in 229 cases. Mayo Clin Proc 1983;58:665-83.

89 Gertz MA, Kyle RA. Primary systemic amyloidosis-a diagnostic primer. Mayo Clin Proc 1989;64:1505-19.

90 Yamano S, Motomiya K, Akai Y, et al. Primary systemic amyloidosis presenting as angina pectoris due to intramyocardial coronary artery involvement: a case report. Heart Vessels 2002;16:157-60.

91 Mueller PS, Edwards WD, Gertz MA. Symptomatic ischemic heart disease resulting from obstructive intramural coronary amyloidosis. Am J Med 2000; 109:181-8.

92 Ishikawa Y, Ishii T, Masuda S, et al. Myocardial ischemia due to vascular systemic amyloidosis: a quantitative analysis of autopsy findings on stenosis of the intramural coronary arteries. Pathol Int 1996;46:189-94.

93 Goffin Y. Microscopic amyloid deposits in the heart valves: a common local complication of chronic damage and scarring. J Clin Pathol 1980:33:262-8.

94 Sequeira-Filho AG, Cunha CL, Tajik AJ, et al. M-mode and two dimensional echocardiographic features in cardiac amyloidosis. Circulation 1981;63:188-96.

95 Daubert JP, Gaede J, Cohen HJ. A fatal case of constrictive pericarditis due to a marked, selective pericardial accumulation of amyloid. Am J Med 1993;94:335-40.

96 Nakata T, Shimamoto K. Cardiac denervation in amyloid polyneuropathy. Lancet 2003;361:1181

97 Jennette JC, Sheps DS, McNeill DD. Exclusively vascular systemic amyloidosis with visceral ischemia. Arch Pathol Lab Med 1982;106:323-7.

98 Ohashi K, Takagawa R, Hara M. Visceral organ involvement and extracellular matrix changes in $\beta 2$-microglobulin amyloidosis $-a$ comparative study with systemic AA and AL amyloidosis. Virchows Arch 1997; 430:479-87.

99 Gejyo F, Odani S, Yamada T, et al. Beta 2 -microglobulin: a new form of amyloid protein associated with chronic haemodialysis. Kidney Int 1986:30:385-90.

100 McAdam KPWJ, Sipe JD. Murine model for human secondary amyloidosis: genetic variability of the acute-phase serum protein SAA response to endotoxins and casein. J Exp Med 1976;144:1121-7.

101 Liepnieks JJ, Kluve-Beckerman B, Benson MD. Characterization of amyloid A protein in human secondary amyloidosis: the predominant deposition of serum amyloid A1. Biochim Biophys Acta 1995;1270:81-6.

102 Gertz MA, Kyle RA. Secondary systemic amyloidosis: response and survival in 64 patients. Medicine 1991;79:246-56.

103 Beydoun SR, Rison RA, Commins D. Secondary amyloidosis as a life-ending event in multifocal motor neuropathy. Muscle Nerve 2001;24:1396-402.

104 Ahmed Q, Chung-Park M, Mustafa K, et al. Psoriatic spondyloarthropathy with secondary amyloidosis. J Rheumatol 1996;23:1107-10.

105 Dubrey SW, Cha K, Simms RW, et al. Electrocardiography and Doppler electrocardiography in secondary (AA) amyloidosis. Am J Cardiol 1996;77:313-15.

106 Stather D, Ford S, Kisilevsky R. Sarcoid, amyloid, and acute myocardial failure. Mod Pathol 1998;11:901-4.

107 Cooper JH. Localised dystrophic amyloidosis of heart valves. Hum Pathol 1983; 14:649-53.

108 Ladefoged C, Rohr N. Amyloid deposits in aortic and mitral valves. A clinicopathological investigation of material from 100 consecutive heart valve operations. Virch Arch A Pathol Anat Histopathol 1984;404:301-12.

109 Looi LM. Isolated atrial amyloidosis: a clinicopathologic study indicating increased prevalence in chronic heart disease. Hum Pathol 1993;24:602-7.

110 Johansson B, Werstedt C, Westermark P. Atrial natriuretic peptide deposited as atrial amyloid fibrils. Biochem Biophys Res Commun 1987;148:1087-92.
111 Lie JT, Hammond PI. Pathology of the senescent heart: anatomic observations on 237 autopsy studies of patients 90 to 105 years old. Mayo Clin Proc 1988;63:552-64

112 Sawabe M, Hamamatsu A, Ito T, et al. Early pathogenesis of cardiac amyloid deposition in senile systemic amyloidosis: close relationship between amyloid deposits and the basement membranes of myocardial cells. Virchows Arch 2003;442:252-7.

113 Allensworth DC, Rice GJ, Lowe GJ. Persistent atrial standstill in a family with myocardial disease. Am J Med 1969:47:775-84.

114 Benson MD, Wallace MR, Teyada E, et al. Hereditary amyloidosis: description of a new American kindred with late onset cardiomyopathy. Arthritis Rheum 1987;30:195-200.

115 Frederiksen H, Gotssche H, Harboe N, et al. Primary familial amyloidosis with severe amyloid heart disease. Am J Med 1962;33:328-48.

116 Hesse A, Altland K, Linke RP, et al. Cardiac amyloidosis: a review and report of a new transthyretin (prealbumin) variant. Br Heart J 1993;70:111-15.

117 Eriksson A, Olofsson BO, Eriksson P. Heart valve involvement in familial amyloidosis with polyneuropathy. Pathol Res Pract 1986;181:563-7.

118 Saraiva MJM, Sherman W, Marboe C, et al. Cardiac amyloidosis: report of a patient heterozygous for the transthyretin isoleucine 122 variant. Scand J Immunol 1999;32:341-6.

119 Saraiva MJM, Costa PP. Molecular biology of amyloidogenesis in the transthyretin related amyloidoses. In: Natvig JB, Forre O, Husby G, et al, eds. Amyloid and amyloidosis, 1990. Dordrecht: Kluwer Academic Publishers, 1991:560-74.

120 Jacobson DR, Pastore RD, Yaghoubian R, et al. Variant-sequence transthyretin (isoleucin 122) in late-onset cardiac amyloidosis in Black Americans. N Engl J Med 1997;336:466-73.

121 Yazaki M, Tokuda T, Nakamura A, et al. Cardiac amyloid in patients with familial amyloid polyneuropathy consists of abundant wild-type transthyretin. Biochem Biophys Res Commun 2000;27:702-6.

122 Goffin YA, Murdoch W, Cornwell GG III, et al. Microdeposits of amyloid in sclerocalcific heart valves: a histochemical and immunofluorescence study. J Clin Pathol 1983:36:1342-9.

123 Yokota T, Okabayashi $\mathrm{H}$, Ishihara $\mathrm{T}$, et al. Immunohistochemical and pathological characteristics of dystrophic amyloid in surgically excised cardiac valves. Pathol Int 1994;44:182-5.

124 Goffin YA, Rickaert F. Histotographic evidence that amyloid deposits in sclerocalcific heart valves and other chronic lesions of the cardiovascular system are related to old thrombotic material. Virch Arch A Pathol Anat Histopathol 1986;409:61-77.

125 Goffin YA, Gruys E, Sorenson GD, et al. Amyloid deposits in bioprosthetic cardiac valves after long-term implantation in man. A new localization of amyloidosis. Am J Pathol 1984; 114:431-42.

126 Mucchiano GI, Cornwell GG III, Westermark P. Senile aortic amyloid. Evidence for two distinct forms of localised deposits. Am J Pathol 1992;140:871-7.

127 Cornwell GG III, Westermark P, Murdoch W, et al. Senile aortic amyloid. A third distinctive type of age-related cardiovascular amyloid. Am J Pathol 1982; 108:135-9

128 Häggqvist B, Näslund J, Sletten K, et al. Medin: an integral fragment of aortic smooth muscle cell-produced lastadherin forms the most common human amyloid. Proc Natl Acad Sci U S A 1999:96:8669-74.

129 Peng S, Westermark GT, Naslund J, et al. Medin and medin-amyloid in ageing inflamed and non-inflamed temporal arteries. J Pathol 2002;196:91-6.

130 Mucchiano GI, Jonasson, Haggqvist B, et al. Apolipoprotein A-I-derived amyloid in atherosclerosis. Its association with plasma levels of apolipoprotein A-I and cholesterol. Am J Clin Pathol 2001;115:298-303.

131 Mucchiano GI, Haggqvist B, Sletten K, et al. Apolipoprotein A-I-derived amyloid in atherosclerotic plaques of the human aorta. J Pathol 2001; 193:270-5.

132 Yamada T, Kakihara T, Kamishima T, et al. Both acute phase and constitutive serum amyloid $\mathrm{A}$ are present in atherosclerotic lesions. Pathol Int 1996;46:797-800.

133 Johnson KH, Sletten K, Hayden DW, et al. Pulmonary vascular amyloidosis in aged dogs. A new form of spontaneously occurring amyloidosis derived from apolipoprotein A1. Am J Pathol 1992;141:1013-19.

134 Ogawa H. Senile cardiac amyloidosis in senescence accelerated mouse (SAM). Jpn Circ J 1988;52:1377-83.

135 Sezer O, Niemöller K, Jakob C, et al. Novel approaches to the treatment of primary amyloidosis. Exp Opin Invest Drugs 2000;9:2343-50.

136 Hall R, Hawkins PN. Cardiac transplantation for AL amyloidosis. BMJ 1994;309:1135-7.

137 Gertz MA, Lacy MQ, Dispenzieri A, et al. Stem cell transplantation for the management of primary systemic amyloidosis. Am J Med 2002;113:549-55.

138 Grazi GL, Cescon M, Salvi F, et al. Combined heart and liver transplantation for familial amyloidotic neuropathy: considerations from the hepatic point of view. Liver Transpl 2003;9:986-92.

139 Gillmore JD, Stangou AJ, Tennent GA, et al. Clinical and biochemical outcome of hepatorenal transplantation for hereditary systemic amyloidosis associated with apolipoprotein Al Gly26Arg. Transplantation 2001;71:986-92.

140 Kolstoe S, Wood S. Perspectives for drug intervention in amyloid diseases. Curr Drug Targets 2004;5:151-8.

141 Pepys MB, Herbert J, Hutchinson WL, et al. Targeted pharmacological depletion of serum amyloid $\mathrm{P}$ component for treatment of human amyloidosis. Nature 2002;417:254-9.

142 Kyle RA, Gertz MA. Primary systemic amyloidosis: clinical and laboratory features in 474 cases. Semin Hematol 1995;32:45-59.

143 Reyners AK, Hazenberg BP, Reitsma WD, et al. Heart rate variability as a predictor of mortality in patients with $\mathrm{AA}$ and $\mathrm{AL}$ amyloidosis. Eur Heart $J$ 2002;23:157-61. 